\title{
Leveraging social change through collective purchasing
}

Book review by Holly A. Chaille



\section{Beyond Alternative Food Networks: Italy's Solidarity Purchase Groups}

Grasseni, C. (2013). Beyond alternative food networks: Italy's solidarity purchase groups. New York: Bloomsbury. Available as hardcover, paperback, and EPUB and PDF eBook. Publisher's website: http://www.bloomsbury.com/us/beyond-alternative-foodnetworks-9780857852298/

Published online March 9, 2014

Citation: Chaille, H. A. (2014). Leveraging social change through collective purchasing [Book review of Beyond Alternative Food Networks]. Journal of Agriculture, Food Systems, and Community Development, 4(2), 177-178. http://dx.doi.org/10.5304/jafscd.2014.042.009

Copyright (C) 2014 by New Leaf Associates, Inc.

$\mathrm{O}$ $\mathrm{n}$ the dedication page of Beyond Alternative Food Networks, Grasseni quotes from Immanuel Kant's Critique of Pure Reason: "There can be no doubt that all our knowledge begins with experience." Her selection may serve as an indicator that Grasseni's experience as a member of a solidarity purchase group (a group of people who purchase directly from growers and producers) is the basis for her argument that these community collaboratives can be powerful structures for addressing and improving more than local food issues. A conscientiously systematic and democratic approach that stresses inclusion as opposed to homogeneity, she posits, can be applied more broadly within communities to address economic sustainability.

Holly A. Chaille blogs at http://beesandcarrots.com and is an advance master gardener through Purdue University Extension. She can be contacted at 1402 Colony Court, Fort Wayne, Indiana 46845 USA; +1-765-631-0262; hachaille@gmail.com
Grasseni's writing style reflects her strong research background; she takes care to explain that as a member of one such solidarity purchase group, the Gruppo di Acquisto Solidale (GAS) that she is highlighting, she is practicing "engaged anthropology," a theoretical term for participating in a process while observing it. In fact, her involvement as a gasista is critical to her research, making her an expert witness for her case.

Grasseni sets out to explain how the food provisioning models utilized in Italy are not merely food buying clubs or access points, but very promising transformative economic models. She argues that healthy GAS models empower their members to think of themselves as more than a collective of consumers. They develop the potential power to become change agents within their local regions, capable of affecting local supply and demand decisions in ways that prioritize people and the environment above cost. 
The book is a fairly quick read, with only five chapters laid out in a scholarly manner, each complete with up-to date citations and notes that can take one further into the field, as it did this reader. There are also numerous notes, a glossary, footnotes, and a very thorough reference list.

Chapter 1 provides an overview of food networks across the globe, including the community supported agriculture (CSA) model common in the United States. A reader hoping to compare CSA and GAS models will learn that they are not all that similar, as CSAs emphasize a farmer-to-customer relationship, a facet of ethical consumerism, whereas a GAS by definition is reliant on the group relationship with the farmer or source of goods. This is an important distinction, as it would seem unlikely that the American habit of "looking out for number one" precludes us from the collective consumer behavior Grasseni describes as the basis for co-production, detailed further in chapters 2 and 3. This is not to imply that we here in the U.S. can't affect change singularly or work together as a group as a GAS does, but it is a point of departure and explains why there is not more discussion in this book of the CSA model.

Chapter 2 focuses on Italy's various food system strategies and begins to flesh out those characteristics of GAS that distinguish it from a collaborative effort - to rebuke habitual consumerism based on ease of acquisition - to a collective imagination and practice of evaluation, deliberation, and problem-solving, capable of reshaping and reprioritizing the local economy.

Chapters 3 and 4 describe the Gruppo di Acquisto Solidale in detail, allowing the reader to glimpse the structure and process from within. Citing specific examples from her experience as a gasista, Grasseni illustrates the alternately painstaking, mundane, and celebratory interactions required among members. These chapters could be construed as a warning to those not inclined to have face-to-face encounters or long meetings over Excel spreadsheets, but it is this due diligence that creates trust and reliability among members and is important in setting the stage for chapter 5 , in which the author's thesis is examined.

Though she repeatedly argues that this type of collective capacity-building is useful in times of crisis, Grasseni's thesis is arguably more applicable when a community is not reeling from corruption or calamity.

In chapter 5 Grasseni cites several incidents in Italy's recent history, such as financial scandal and a well-publicized international horse-meat contamination, as the crisis points that gave GAS and similar networks the opportunity to develop. This seems to diminish her thesis, however, because it suggests that GAS are opportunistic and reactive, filling a need at a point of mistrust. Throughout the book Grasseni emphasizes transformation as a result of purposeful discernment. While it is certain that greed and unethical practices will make communities question leadership, the birth, growth, and sustainability of GAS, CSAs, or any other group of like-minded and willing members can affect great and permanent change at any point in time — and perhaps with greater success when approached with great deliberation and forethought.

Advocates of local food may find this book invigorating in its ability to articulate how food networks hold the promise of powerful movements from a grassroots level. Though this is not a book that depicts the CSA model Americans are familiar with, it does describe in detail several strategies currently used in Italy that could provide an adaptable model for the future of U.S. local food networks.

The author is not new to the subject of food networks, and her writing suggests her commitment to detailed research. A social anthropologist, Grasseni's CV includes fellowships at Radcliffe and Harvard, where she is currently a visiting scholar.

Grasseni challenges the reader to ponder a variety of questions she has come across in her studies, including whether a truly socialist network of citizens can change our current reliance on commodity-based, cheap, unsustainable food chains, or if we have gone too far in our destruction of the environment and our own willingness to sacrifice personal health to recover.

The book is written more for researchers, planners, and perhaps those food system planners who collect works related to the field. Not a howto guide, Beyond Alternative Food Networks does more in the way of offering a philosophy of economics through a social-science lens. 